\title{
Using intervention mapping for the development of a targeted secure web-based outreach strategy named SafeFriend, for Chlamydia trachomatis testing in young people at risk
}

Kevin ATM Theunissen ${ }^{1}$, Christian JPA Hoebe ${ }^{1,2}$, Rik Crutzen ${ }^{3}$, Chakib Kara-Zaïtri ${ }^{4}$, Nanne K de Vries ${ }^{3}$, Jan EAM van Bergen ${ }^{5,6,7}$, Marianne AB van der Sande ${ }^{5,8}$ and Nicole HTM Dukers-Muijrers ${ }^{1,2^{*}}$

\begin{abstract}
Background: Many young people at high risk for Chlamydia trachomatis $(\mathrm{Ct})$ are not reached by current sexual health care systems, such as general practitioners and public sexual health care centres (sexually transmitted infection clinics).Ct is the most frequently diagnosed bacterial sexually transmitted infection (STI) among sexually active people and in particular young heterosexuals. Innovative screening strategies are needed to interrupt the transmission of $\mathrm{Ct}$ among young people and connect the hidden cases to care.

Methods: Intervention Mapping (IM), a systematic approach to develop theory- and evidence-based interventions, was used to develop a strategy to target Ct testing towards young people who are currently hidden to care in The Netherlands. Both clinical users (i.e. sexual health care nurses) and public users (i.e., young people at risk for Ct) were closely involved in the IM process. A needs assessment study was carried out using semi-structured interviews among users $(\mathrm{N}=21)$, a literature search and by taking lessons learned from existing screening programmes.

Theoretical methods and practical applications to reach high risk young people and influence testing were selected and translated into specific programme components.

Results: The IM approach resulted in the development of a secure and web-based outreach Ct screening strategy, named SafeFriend. It is developed to target groups of high-risk young people who are currently hidden to care. Key methods include web-based Respondent Driven Sampling, starting from young Ct positive sexual health care centre clients, to reach and motivate peers (i.e., sex partners and friends) to get tested for Ct. Testing and the motivation of peers were proposed as the desired behavioural outcomes and the Precaution Adoption Process Model was chosen as theoretical framework. End users, i.e., young people and sexual health care nurses were interviewed and included in the development process to increase the success of implementation.

Conclusions: IM proved useful to develop an intervention for targeted Ct testing among young people. We believe this to be the first web-based outreach screening strategy which combines chain referral sampling with the delivery of targeted Ct testing to high risk young people within their sexual and social networks.
\end{abstract}

Keywords: Intervention mapping, Chlamydia trachomatis, Screening, Partner notification, Web-based respondent driven sampling, Social networks, Sexual networks, Peer influence

\footnotetext{
* Correspondence: nicole.dukers@ggdzl.nl

'Department of Sexual Health, Infectious Diseases and Environmental Health,

Public Health Services South Limburg, Geleen, The Netherlands

${ }^{2}$ Department of Medical Microbiology Maastricht Infection Centre (MINC),

School for Public Health and Primary Care (CAPHRI), Maastricht University

Medical Centre (MUMC+), Maastricht, The Netherlands

Full list of author information is available at the end of the article
} 


\section{Background}

Testing and treating are essential strategies in Chlamydia trachomatis $(\mathrm{Ct})$ control to interrupt the inherent transmission chain [1]. In many countries, including the Netherlands, positivity rates of $\mathrm{Ct}$ have increased in the past years [2-4]. Ct is thereby the most frequently diagnosed bacterial sexually transmitted infection (STI) among sexual active people and in particular young heterosexuals. Young people below 25 years of age comprise a major risk group for $\mathrm{Ct}$ control, because they show constant high rates of sexual risk behaviour and potentially bear the largest burden of STI sequelae in terms of reproductive morbidity [5].

Web-based Ct screening programmes have improved the access to sexual health care beyond the sexual health care centre and general practitioners (GPs) by engaging young people in discussions about sexual health, increasing home-based testing, and enhancing the management of $\mathrm{Ct}$ patients and re-screening positives [6-9]. Unfortunately, the success of such early initiatives was limited in the Netherlands (e.g., Chlamydia Screening Implementation Program "CSI") and in other counties $[8,10,11]$. One of the reasons for this was that such initiatives did not readily reach the targeted high-risk young people $[8,10,11]$, leaving this group largely hidden to health care providers. Therefore there is an urgent need to find new ways to tap into such hidden key populations and find a natural way of motivating them to access sexual health care [12]. To clarify the concept, a key population for a given infection consists of members who are either infected or have a very high risk of acquiring the infection. Reason for having (high risk for) infection is the membership to high risk sexual and social networks. Typically, infections thrive in such networks which provide the right vehicle for transmission of the infection taking advantage of the inherent risky behaviour and social proximity $[13,14]$. Currently, a significant number of members of such network remain completely invisible to care (hidden key population).

Members of the social and sexual networks surrounding $\mathrm{Ct}$ positives typically showed high risk $[15,16]$; these networks are important targets for interventions [17]. Information about STI can be readily spread within a social network and thereby influence risk behaviour such as unprotected sex practices [15,17]. Furthermore, networks can overlap whereby a social network creates a venue to meet new sex partners [15,17]. There is now a growing body of evidence on the high success potential of network based interventions, e.g. by using chain referral sampling methods such as web-based Respondent Driven Sampling (web-based RDS) and peer influence to reach hitherto hidden networks [18]. The basic idea behind RDS is that selected young people are recruited as seeds or ambassadors who themselves motivate others in their own networks to get tested, and so on. The RDS methodology has already proven its worth in other public health areas (e.g., health promotion) and target populations (e.g., injection drug users and HIV patients) [19-21].

This paper describes the development of an innovative secure web-based outreach Ct screening strategy, whereby young people at high risk for $\mathrm{Ct}$ (re)-infection will be targeted and encouraged to go for testing. The project is carried out by one of the eight coordinating public sexual health care centres (STI clinics) in the Netherlands, where the intervention will be developed, tested and implemented. The objective is to develop a cost-effective and sustainable web-based outreach screening strategy for reducing the patient's and population's Ct burden, and improving the timing of care. The Intervention Mapping (IM) protocol can be used to guide the systematically development of the intervention based on theory and evidence, which should increase the likelihood of developing an effective intervention [22]. IM has already been applied in different populations and study areas such as drug users, condom use, and stress related mental disorders [23-25], but never in the development of $\mathrm{Ct}$ screening programmes among high risk young people.

\section{Methods}

\section{Step 1: Needs assessment}

The Intervention Mapping process starts with a need assessment to analyse a specific health problem within a target population and associated important stakeholders. Furthermore, behavioural and environmental risk factors that contribute to the health problem are identified and the underlying determinants are explored. At the end the programme outcomes are stated. To plan and guide the need assessment the PRECEDE-model is used [26].

The Dutch national STI policy targets were explored in order to identify expectations from practical and political stakeholders. A literature search was conducted reporting on $\mathrm{Ct}$ prevalence in different population groups, including young people, and existing strategies for $\mathrm{Ct}$ control, why these strategies failed or succeeded, and which methods were cost-effective to reach high risk young people. Furthermore, semi-structured interviews were held among $\mathrm{Ct}$ positive young people ( 8 women and 13 men) who were between 17 and 24 years old and visited the sexual health care centre South Limburg for $\mathrm{Ct}$ treatment. They were from various ages, sexual orientation, educational levels and ethnicity. They were interviewed about partner notification (PN) to find out the determinants to motivate peers to test for Ct. Ethical approval of the Regional Medical Ethics committee in the Netherlands was not necessary, because participants in these interviews were not "subjected to procedures or required to follow certain rules of behaviour" [27]. Based on the needs assessment using the PRECEDE-model (Figure 1), the health 
problem, behavioural and environmental factors, the underlying determinants and the target group were defined, resulting in two desired behavioural outcomes that were selected to be targeted by the intervention.

\section{Step 2: Preparing matrices of change objectives}

In step 2, each of the behavioural outcomes is broken down into performance objectives, i.e. the actions that expectedly lead to the desired outcome. For each performance objective, the most important and changeable determinants are stated based on theoretical models for behavioural change. Combining the performance objectives with the determinants identified results in matrices that include the change objectives that guide the intervention development process.

The performance objectives and most important and changeable determinants were selected based on previous studies, the results of the semi-structured interviews and the Precaution Adoption Process Model (PAPM) [28]. The model comprises of a stage theory that ranges from unaware of a problem to action and maintenance of a specific behaviour (e.g., Ct testing and motivating network members to test). This model was chosen, because it emphasizes that hazard responses are influenced by behaviours and opinions of peers, which is in line with the underlying of social and sexual networks surrounding Ct positives. A person's decision concerning the need to test is influenced by the opinion and actions of peers and not just by specific beliefs about the hazard that lead to rational and independent decisions. This social influence may occur at several stages of the model.

\section{Step 3: Selecting theory-informed intervention methods and practical applications}

In step 3, theory-informed intervention methods are selected to create changes in the determinants of the behavioural outcomes. The relevance of methods for a particular project and the changeability that can be realized with a particular method guides this selection process. Practical applications that fit the target population and context are then translated from these theoryinformed intervention methods.

Before a final list of methods was determined on the basis of existing evidence and theory, theoretical methods were explored and analysed by a small panel of experts consisting of researchers, prevention experts, informaticsspecialists, nurses and medical doctors. The experts then transformed the methods into practical applications taking into account the parameters of use, the literature review and conducted semi-structured interviews.

\section{Step 4: Producing program components and materials}

In this step, the practical applications are combined and translated into programme components and specific materials. During this process several end users are included to select the best program design that fits the user's preferences. The intervention is then pilot-tested among some members of the target population. Eventually, necessary adjustments are made and the definitive intervention developed.

The intervention was constructed, tested and refined with close involvement of high risk young people and sexual health care nurses. The selected applications were incorporated into two websites: (1) a smart and highly interactive website for young people to communicate

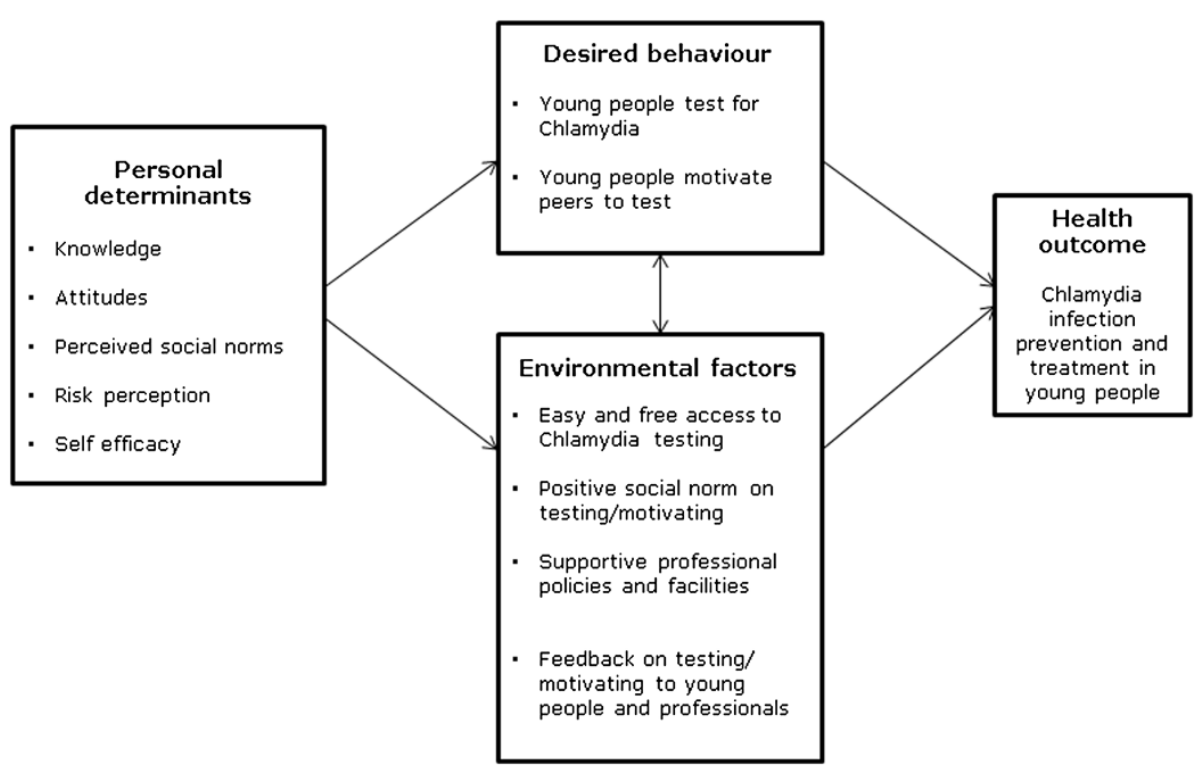

Figure 1 Needs assessment using a simplified PRECEDE model (see Methods and Tables). 
and motivate those at high risk in their social and sexual networks and (2) another website for sexual health care professionals to start recruitment-chains and oversee the process of home-test requests. The final name and lookand-feel of the intervention were set after pre-testing it among young people. The first pre-test of the intervention will be conducted among young people (age $\leq 25$ years) visiting the public sexual health care centre South Limburg for $\mathrm{Ct}$ treatment. Evaluation will then be done to identify facilitating factors and barriers to use and the application is refined further (specific guidance for graphic designers and programmers).

The last two steps of the IM protocol, step 5 and 6, are outside the scope of this paper and are described briefly here.

Step 5: Planning program adoption, implementation, and sustainability

An implementation plan is made to deploy the intervention to a successful outcome. End users and implementers of the intervention are identified and implementation objectives are stated considering dissemination, adoption, implementation and maintenance of the intervention.

Health care professionals (e.g., sexual health care nurses, medical doctors) and policy makers were involved from the start of the project by regular team meetings. They are the key linkage group for the success of the development and implementation and have therefore been involved in the entire research process. The ultimate goal is national implementation in sexual health care centres and the future expansion to GPs will be explored.

\section{Step 6: Planning for evaluation}

In the final step of intervention mapping, an evaluation plan and associated criteria are set up. The level of evaluation is chosen and indicators and measures determine to evaluate the effects and process of the intervention. All program objectives are defined in a measurable form.

To assess whether the intervention leads to changes in determinants and thereby in a change in behaviour of young people (i.e., Ct testing and motivate high risk young people to test for $\mathrm{Ct}$ ) a plan for the quantitative and qualitative evaluation was made. Factors that may hinder or facilitate the use of the intervention will be reviewed in the course of this project and strategies will be explored to positively affect intervention use.

\section{Results}

\section{Step 1: Needs assessment}

\section{Health problem and target group}

The needs assessment started with a literature search and the exploration of national stated aims which revealed that young people below 25 years of age comprise a major risk group for $\mathrm{Ct}$ control, because they show constant high rates of sexual risk behaviour and potentially bear the largest burden of STI sequelae in terms of reproductive morbidity [5]. Every year, there is a large new accretion of about 200,000 susceptible sexually active Dutch young people, although not all are at high risk for acquiring $\mathrm{Ct}$ [1]. Estimates about the total burden of $\mathrm{Ct}$ in 15-30-year-olds suggest 60.000 new infections yearly [29], with an estimate of only 30.000 infections diagnosed in sexual health care centres and by GPs [Personal communication dr. I van den Broek, based on available data from STI centres and GP-surveillance, [2,30]. Hence, half of the $\mathrm{Ct}$ infections remain undetected and hidden to care and there is an urgent need to significantly increase $\mathrm{Ct}$ testing rates among young people at high risk. Young people receive and share information about STI and associated testing through their peers, i.e. a combination of sex partners and friends [17,31]. Their behaviours, attitudes and actions in respect to STIs are strongly influenced by their peers who are therefore key change agents [17,32]. There is clear evidence of high STI/Ct prevalence in social networks surrounding STI positive people [15,16,33,34]. Such networks thrive on high behavioural risk and therefore provide a rich conduit for rapid STI spread and reinfection [16,17]. Based on the health problem and selected target group two desired behavioural outcomes were formulated: a) High risk young people ( $\leq 25$ years of age) get tested for $\mathrm{Ct}$, and b) motivate peers via their social and sexual network to get tested.

\section{Determinants for $\mathrm{Ct}$ testing and motivating peers to test}

Several behavioural barriers for testing among young people have been identified from the literature search (i.e., Table 1). For example the level of knowledge of STI; Ct being an asymptomatic disease, the connection between $\mathrm{Ct}$ and fertility complications and current testing options [35-37]. Another barrier includes misperceived vulnerability; young people do not think they are at risk for $\mathrm{Ct}$ $[35,36,38]$. Embarrassment about the need for testing and fear of a positive test result also plays a role $[36,38,39]$. Shame and fear may be enforced when the provider is a family doctor and young people are charged for testing (note that Dutch sexual health care centres test free of charge) [37-39]. Home-based test were found to be acceptable among young people and could be used as a facilitator factor in testing [9,39-41].

Barriers related to motivate peers to get tested for $\mathrm{Ct}$ include fear of stigmatization among peers, repercussion (e.g. aggression), blaming the other, availability of contact details and the level of emotional commitment [38,42-44].

The analyses of the 21 semi-structured interviews showed several barriers and facilitators related to motivating peers to get tested for $\mathrm{Ct}$. Ct positive young people can feel embarrassed about their positive Ct test result when motivating peers to get tested. Some indicated that 
Table 1 Determinants for Chlamydia (Ct) testing and motivating peers for $\mathrm{Ct}$ testing among young people by systematic literature search (March 2012) and semi-structured interviews $(n=21)$

\begin{tabular}{cc}
\hline Ct Testing & Motivating peers \\
\hline Personal determinants & Personal determinants
\end{tabular}

Knowledge about:

Knowledge about the transmission of $\mathrm{Ct}$ among sexual and social

- STI and in particular asymptomatic disease [35-37] network members [interviews]

- Ct effects [36,37,39]

- Ct testing methods [36,37]

Fear of parental notification [36]

Attitudes towards testing:

- Shame about Ct testing [37-39]

- Embarrassment about Ct testing [36-39]

- Fear of test results [36,38,39]

- Fear of testing procedure [37,39]

Attitudes towards motivating:

- Perceived stigmatization/embarrassment [42-44], interviews

- Emotional commitment with peers [42,44], interviews

- Personal health benefit (re-infection) [42], interviews

- Blaming towards sexual partners [42]

- Fear of reaction (e.g. aggression) [42-44], interviews

Perceived social norms of Ct testing among peers [38,39], interviews

Perceived social norm of motivation among peers [interviews]

Availability and accessibility of contact details*

Risk perception towards testing:

- Awareness of vulnerability/risk for Ct

$[35,36,38]$

[42-44], Interviews

- Awareness of severity of Ct [36,38]

Self-efficacy:

- Afraid to visit public health services [37], interviews

* will be excluded in this study, because this determinant can not be changed.

Table 2 Performance and change objectives for the behavioural outcome: high risk young people get tested for Chlamydia (Ct)

\begin{tabular}{|c|c|c|c|c|c|}
\hline \multicolumn{6}{|c|}{ Determinants } \\
\hline $\begin{array}{l}\text { Performance } \\
\text { objectives }\end{array}$ & Knowledge & Attitude & $\begin{array}{l}\text { Perceived social } \\
\text { norms }\end{array}$ & Risk perception & Self-efficacy \\
\hline \multirow[t]{2}{*}{$\begin{array}{l}\text { PO1.1: Young people } \\
\text { appraise effects of } \mathrm{Ct} \\
\text { and personal risk }\end{array}$} & $\begin{array}{l}\text { K1.1: Describe } \\
\text { different STI and in } \\
\text { particular } \\
\text { asymptomatic } \\
\text { diseases }\end{array}$ & $\begin{array}{l}\text { A1.1: Express positive } \\
\text { attitude towards self } \\
\text { assessment of } C t \text { risk }\end{array}$ & & $\begin{array}{l}\text { R1.1: Aware of the } \\
\text { possibility of getting a } \\
\text { Ct infection }\end{array}$ & \\
\hline & $\begin{array}{l}\text { K1.2: Describe Ct } \\
\text { effects }\end{array}$ & & & & \\
\hline $\begin{array}{l}\text { PO1.2: Young people } \\
\text { decide to get tested } \\
\text { for Ct }\end{array}$ & $\begin{array}{l}\text { K1.3: Describe test } \\
\text { procedure and test } \\
\text { options for } \mathrm{Ct}\end{array}$ & & & $\begin{array}{l}\text { R1.2: Aware of the } \\
\text { health risk of not } \\
\text { getting tested }\end{array}$ & \\
\hline $\begin{array}{l}\text { PO1.3: Young people } \\
\text { ask for } \mathrm{Ct} \text { testing }\end{array}$ & & & & & $\begin{array}{l}\text { SE1.1: Express confidence } \\
\text { in ability to ask for testing } \\
\text { option (home based test } \\
\text { kits or appointment STI } \\
\text { centre) }\end{array}$ \\
\hline $\begin{array}{l}\text { PO1.4: Young people } \\
\text { get tested for } \mathrm{Ct}\end{array}$ & & $\begin{array}{l}\text { A1.2: Express positive } \\
\text { attitude towards test } \\
\text { procedure and results. }\end{array}$ & $\begin{array}{l}\text { SN1.1: Recognize } \\
\text { social acceptance of } \\
\text { Ct testing among } \\
\text { young people }\end{array}$ & & \\
\hline
\end{tabular}


in case of a casual sex partner they would like to notify anonymously. Fear of aggression of sex partners can also discourage $\mathrm{Ct}$ positive young people to motivate peers. Interviewees expressed emotional commitment to their sex partners and felt responsible for informing them about the Ct risk. They were aware of the possible health risks for direct and indirect sex partners, whereas others were afraid of re-infection. As stated by one interviewee: "Partner notification is self-evident, when you do not warn your steady partner, you will get re-infected". Social influence plays also an important role. Several interviewees were notified about their $\mathrm{Ct}$ risk via their sex partners and then visited a sexual health care centre. They also indicated that friends visited a sexual health care centre after talking to them about $\mathrm{Ct}$ testing and their own positive test result. As noted by one interviewee: "We [friends] talk about everything. We do not have any problems to talk about Ct positive test results".

\section{Step 2: Preparing matrices of change objectives}

For each of the 2 behavioural outcomes 4 performance objectives were defined (i.e., Tables 2 and 3). Firstly, young people should be able to appraise their own and others Ct risk behaviour. Secondly, if necessary, young people should decide to get tested and motivate peers who are at risk for $\mathrm{Ct}$ to get tested. Thirdly, planning for getting tested or motivating peers is another objective which will lead to the fourth objective of actually getting tested and motivating other young people at risk for $\mathrm{Ct}$. The following determinants were identified as most important and changeable: knowledge, self-efficacy, risk perception, social norms and attitudes. Finally, a matrix of change objectives was developed for each behavioural outcome.

The treatment and follow up for re-testing is already included in the current sexual health care practice and is therefore not described within the matrices.

\section{Step 3: Selecting theory-informed intervention methods and practical applications}

As a result from the initial needs assessment and the matrices of change in step 2, a web-based RDS was used to select peers to motivate young people and encourage them to attend $\mathrm{Ct}$ testing, thereby motivating high-risk young people through their own social and sexual network. Web-based RDS was judged highly promising and feasible in high-risk young people, because it has been successfully used before in a group of young people [18]. The concept of using peer influence and chain-referral sampling has already worked well to target "those in need" in complex networks but never used in Ct control in young people $[19,45,46]$. In our strategy sampling begins with $\mathrm{Ct}$ positive young people attending the South Limburg sexual health care centres and proceeds in waves recruiting more targeted contacts from hithertohidden sexual and social networks. Participants select friends based on their knowledge of the extent to which these friends need or use appropriate care. The person who begins the chain-referral sampling within a given high risk network is already tested for $\mathrm{Ct}$, which increases perceived social norms. To improve the chance of the targeted contact to decide for testing, messages and home-based test kits will be used. Other supporting methods geared to improve testing and motivating include tailoring, personalize risk, modelling, consciousness raising, elaboration, mobilizing social support and self re-evaluation (i.e., Tables 4 and 5).

\section{Step 4: Producing program components and materials}

As a result of the selected methods and practical applications the deliverable will be an outreach $\mathrm{Ct}$ screening strategy based on a secure web-based RDS engine, with an online interface specially written for young people to recruit and motivate peers. This website is named www. SafeFriend.nl. The use of the web was judged promising during this IM process, because many young individuals

Table 3 Performance and change objectives for the behavioural outcome: young people motivate peers to get tested for Chlamydia (Ct)

\begin{tabular}{|c|c|c|c|}
\hline \multicolumn{4}{|c|}{ Determinants } \\
\hline Performance objectives & Knowledge & Attitude & Perceived social norms \\
\hline $\begin{array}{l}\text { PO2.1: Young people appraise } \\
\text { peers to get tested }\end{array}$ & $\begin{array}{l}\text { K2.1: Recognize the risk of } \mathrm{Ct} \\
\text { among social and sexual network } \\
\text { members }\end{array}$ & & \\
\hline $\begin{array}{l}\text { PO2.2: Young people decide } \\
\text { to motivate network members } \\
\text { for testing }\end{array}$ & & $\begin{array}{l}\text { A2.1: Feel responsible to motivate } \\
\text { high risk young peers }\end{array}$ & \\
\hline $\begin{array}{l}\text { PO2.3: Young people plan to } \\
\text { motivate peers }\end{array}$ & & $\begin{array}{l}\text { A2.2: Express positive attitude } \\
\text { towards the motivation of peers to } \\
\text { get tested }\end{array}$ & \\
\hline PO2.4: Young people motivate peers & & & $\begin{array}{l}\text { SN2.1: Recognize social acceptance } \\
\text { among young people to motivate } \\
\text { peers at high risk for } \mathrm{Ct}\end{array}$ \\
\hline
\end{tabular}


have an email address and/or mobile phone to reach them. Using messages via email and/or mobile phone young people can motivate their sex partners and/or friends. The message will be brief and contains carefully worded text to alert the receiver of possible $\mathrm{Ct}$ risk, provide options for $\mathrm{Ct}$ testing and modelling (i.e., peers who test). To increase the likelihood of use the exact content of this message can be partly adapted (i.e., name or anonymous, level of language) by the user who sends it. After login and system user verification the person is offered tailored information on sexual health and likely $\mathrm{Ct}$ risk. They will be prompted with a brief questionnaire and the answers are automatically assessed to decide to offer him or her a home-based Ct test. Home-based testing has proven feasible and effective in other screening programs, however, such internet-delivered testing is yet to be included in regular care in public sexual health care centres or other care settings. The new recruit is then encouraged to motivate at that moment or at a later stage others who will then go through the same procedure. It should be noted that within the website in some cases a young individual will be asked to visit the sexual health care centre as they are likely to require more sexual health care than Ct testing alone. Necessary facilities like computers and home-based $\mathrm{Ct}$ test kits will be in place at the moment the intervention is implemented in practice. Overall, the use of the SafeFriend website by young people is self-initiated and not guided by the care professionals. The exception is the first recruitment step where the $\mathrm{Ct}$ positive young people at the sexual health care centre are motivated and supported by the nurses to use the intervention. For this, a second designed interface is accessed by the nurse during the consultation visit (the moment that in routine care $\mathrm{PN}$ is discussed). This

\section{Table 4 Methods and applications to get high risk young people tested for Chlamydia (Ct)}

\begin{tabular}{|c|c|c|c|}
\hline & Methods & Parameters for use & Applications \\
\hline \multicolumn{4}{|l|}{ Knowledge } \\
\hline $\begin{array}{l}\text { K1.1: Describe different STI and in } \\
\text { particular asymptomatic diseases }\end{array}$ & -Tailoring & $\begin{array}{l}\text {-Tailoring variables or factors } \\
\text { (e.g., socioeconomic status) }\end{array}$ & $\begin{array}{l}\text { AP1.1: Online tailored information about STI } \\
\text { based on current knowledge and } \\
\text { Socioeconomic Status (SES) }\end{array}$ \\
\hline $\begin{array}{l}\text { K1.2: Describe Ct effects } \\
\text { K1.3: Describe test procedure and } \\
\text { test options for Ct }\end{array}$ & -Elaboration & $\begin{array}{l}\text {-Individuals with high motivation, } \\
\text { messages that are personally } \\
\text { relevant and easily understandable. }\end{array}$ & $\begin{array}{l}\text { AP1.2: Information about the different Ct test } \\
\text { options and procedures using videos and } \\
\text { images. }\end{array}$ \\
\hline
\end{tabular}

\section{Attitude}

A1.1: Express positive attitude towards self assessment of Ct risk

A1.2: Express positive attitude towards test procedure and results.

Perceived social norms

SN1.1: Recognize social acceptance of $\mathrm{Ct}$ testing among young people

\section{Risk perception}

R1.1: Aware of the possibility of getting a Ct infection

R1.2: Aware of the health risk of not getting tested

\section{self-efficacy}

SE1.1: Express confidence in ability to ask for testing option (home based test kits or appointment STI centre)

-Self-re-evaluation -Stimulation of both cognitive and affective appraisal of self-image

-Modelling

-Elaboration

-Modelling

-Mobilizing social

-Support

-Personalize risk

-Consciousness

-Raising

-Planning coping responses
-Attention and identification with model

-Individuals with high motivation, messages that are personally relevant and easily understandable.

-Availability of social and sexual network

-Messages are personal and results are compared to absolute and normative standards.

-Can use feedback

-Identification of potential barriers and solutions
AP1.3: Stimulation via visual effects (videos, and images) and questions to self assess sexual behaviour.

AP1.4: Messages from friends/sex partners to motivate young people to self assess their sexual behaviour

AP1.2: Information about the different Ct test options and procedures using videos and images.

AP1.5: Via personalized or anonymous messages from peers young people are encouraged to get tested for Ct. Information about Ct test options and informs that a friend or sex partner already asked for a Ct test.

AP1.6: Risk assessment questionnaire will be provided and a personalized report about the acquired $\mathrm{Ct}$ risk and an advice about $\mathrm{Ct}$ testing is provided to the person.

AP1.7: Reminders will be send to young people who did not yet ask for a Ct test.

AP1.8: Young people will be informed about the possibility and advantages of home-based Ct test kits. These test kits are free, anonymous and easy to use. 
Table 5 Methods and applications for young people to motivate peers to get tested for Chlamydia (Ct)

\begin{tabular}{|c|c|c|c|}
\hline & Methods & Parameter for use & Applications \\
\hline \multicolumn{4}{|l|}{ Knowledge } \\
\hline \multirow{2}{*}{$\begin{array}{l}\text { K2.1: Recognize the transmission } \\
\text { of Ct among social and sexual } \\
\text { network members }\end{array}$} & -Tailoring & $\begin{array}{l}\text {-Tailoring variables or factors } \\
\text { (e.g., socioeconomic status }\end{array}$ & \multirow{2}{*}{$\begin{array}{l}\text { AP2.1: Online information about the } \\
\text { transmission of Ct among social and sexual } \\
\text { network via videos and images. }\end{array}$} \\
\hline & - Elaboration & $\begin{array}{l}\text {-Messages that are personally relevant, } \\
\text { easily understandable and include direct } \\
\text { instructions }\end{array}$ & \\
\hline \multicolumn{4}{|l|}{ Attitude } \\
\hline $\begin{array}{l}\text { A2.1: Feel responsible to } \\
\text { motivate high risk young peers }\end{array}$ & $\begin{array}{l}\text {-Elaboration } \\
\text { Modelling }\end{array}$ & \multirow{2}{*}{$\begin{array}{l}\text {-Messages that are personally relevant, } \\
\text { easily understandable and include direct } \\
\text { instructions - Attention and identification } \\
\text { with model }\end{array}$} & \multirow{2}{*}{$\begin{array}{l}\text { AP2.1: Online information about the } \\
\text { transmission of } \mathrm{Ct} \text { among social and sexual } \\
\text { network via videos and images. AP2.2: Via } \\
\text { personalized or anonymous messages from } \\
\text { peers young people will be encouraged to } \\
\text { motivate their own friends/sex partners. }\end{array}$} \\
\hline $\begin{array}{l}\text { A2.2: Express positive attitude } \\
\text { towards the motivation of peers } \\
\text { to get tested }\end{array}$ & & & \\
\hline \multicolumn{4}{|l|}{ Perceived social norms } \\
\hline \multirow{2}{*}{$\begin{array}{l}\text { SN2.1: Recognize social } \\
\text { acceptance among young } \\
\text { people to motivate peers at high } \\
\text { risk for Ct }\end{array}$} & -Modelling & -Attention and identification with model & \multirow{2}{*}{$\begin{array}{l}\text { AP2.2: Via personalized or anonymous } \\
\text { messages from peers young people will be } \\
\text { encouraged to motivate their own friends/ } \\
\text { sex partners. }\end{array}$} \\
\hline & $\begin{array}{l}\text { - Mobilizing social } \\
\text { support }\end{array}$ & -Availability of social and sexual network & \\
\hline
\end{tabular}

interface enables the nurse to start the recruitment-chain and to oversee the process of further home-test requests. The young Ct positive client can motivate others during the consultation (like in provider referral) and/or at a later moment at home (like in patient-referral). Of course the clients may choose not to motivate others, without any further consequences for their own care. As the actions on motivating others are standardly registered (coded) the intervention yields systematic data on $\mathrm{PN}$, data which are currently lacking.

\section{Discussion}

Intervention Mapping has been used to develop a webbased outreach strategy, named SafeFriend, for Ct testing in young people at risk. The intervention will be used to target high risk young people as opposed to the current wider web-based $\mathrm{Ct}$ screening strategies which have used a more opportunistic [6,9] or population approach $[8,10]$. It is believed that the current research project is the first web-based outreach screening strategy that combines a web-based RDS method with the delivering of targeted $\mathrm{Ct}$ screening to high risk young people using peer influence, starting from young $\mathrm{Ct}$ positive sexual health care centre clients. The sexual health care setting acts as a sustainable source of $\mathrm{Ct}$ positive young people and thereby provides continued access to more hard-to-reach group of high-risk young people in their networks. Specifically, this strategy aims to extend $\mathrm{Ct}$ prevention beyond sexual networks by also recruiting high-risk young people within social networks.

The attitudes and behaviours of young people in respect of sexual behaviour and STIs are strongly influenced by their peers [15,17,32]. Peer influence regarding STI screening is therefore an important strategy to reach high risk young people for STI testing. The Ct positive young people, who begin the web-based chain referral sampling in the proposed intervention, will have experiences with $\mathrm{Ct}$ testing and treatment. Their specific knowledge and positive attitudes about $\mathrm{Ct}$ testing could make them ideal peers to communicate messages within their sexual and social networks. However, the reliance on the success of motivation and engaging peer networks using peer influence could be reason for some concern. Personal and social sensitivities regarding STI (i.e., stigmatization, confidentiality and privacy) can be important barriers and can counter the success of peer influence. To ensure medical confidentiality and provide a secure web-based screening strategy, we enable persons to decide for themselves which personal information they reveal to their own chosen sex partners and/or friends; personal information will, in all cases, be completely invisible to all other peers. Having said this, STI is a sensitive and personal topic, especially if a STI is diagnosed, still other studies have found that youngsters did share their results with peers (i.e., $93 \%$ in CSI) [31].

The use of online Ct testing of larger populations and associated home-based test kits is increasing worldwide and proved already feasible and acceptable among young people $[7,9,40,41,47]$. It creates easy access to testing and overcomes barriers such as the time required for travelling, transportation and fear of anonymity loss [48]. Despite these advantages, the cost per case detected and treated is high due to low participation and $\mathrm{Ct}$ positivity rates $[8,10]$, caused by targeting sexual networks only (i.e., thereby missing non-sexual high-risk contacts) or by taking a population based approach (i.e., including lower risk individuals). The developed strategy, is expected to be more targeted and cost-effective for $\mathrm{Ct}$ control starting 
from high risk young people (i.e., Ct positive sexual health care clients) and also including social networks (i.e., non sexual high-risk individuals).

In addition, the intervention should increase re-infection control by facilitating also web-based PN. Using a webbased RDS method will respectively reduce the delay of sex partner's testing and increases the number of detected $\mathrm{Ct}$ infections among sex partners and friends [41]. For an actual reduction of $\mathrm{Ct}$ transmission and re-infection effective $\mathrm{Ct}$ treatment is necessary. In two previous studies, more than $90 \%$ of sex partners and positive patients being tested with home-based test kits received treatment $[40,41]$.

Although web-based PN systems are emerging [43,49], comprehensive evaluations to determine the effectiveness of these systems are limited: data regarding sociodemographics and actual outcomes (i.e., testing and treatment of partners) are not systematically collected. To obtain more insight into infection patterns and partner management, sexual and social contacts should be linked with socio-demographics at the individual and network level. The proposed intervention will yield systematic data on infections patterns and PN. The methodology in this paper (i.e., web-based RDS) in combination with social network techniques can structurally identify network clusters and the socially prominent characteristics associated with the clusters. Identifying and understanding the boundaries and bridges within a network will also be possible and can provide useful information about the extent of network penetration. Furthermore, available data show that current PN practices, which are mainly by patient referral $[50,51]$, could be improved significantly when there is more provider-oversight and support [34,42,47], a strategy that is also accommodated in our intervention.

The intervention will be developed, tested and implemented within a public health care service involved in STI control. An important pillar of public healthcare is the support of vulnerable groups in society. If a patient is less capable to warn his/her partner, due to low selfefficacy or misperceived severity, public health care professionals may be inclined to take responsibility in the interest of both the patient and his/her sex partner (i.e., prevention and re-infection control). However, tension exists between achieving benefits for whole populations and protecting the individual's rights [52]. The intervention therefore facilitates both patient and provider referral, creating a digital environment where clients can voluntarily, but with the support and oversight of sexual health care nurses motivate peers to get tested.

\section{Conclusion}

In conclusion, IM was a useful tool in developing an intervention for targeted Ct testing among high risk young people. The proposed intervention SafeFriend will be the first web-based outreach $\mathrm{Ct}$ screening strategy for high risk young people which includes web-based chain referral sampling to motivate peers (i.e., sex partners and fiends) to get tested for Ct. The intervention will complement existing sexual health care, by introducing the Internet to targeted $\mathrm{Ct}$ screening. It builds on lessons learned form a large-scale Dutch population based $\mathrm{Ct}$ screening programme using home-based test kits and adds to current initiatives to strengthen web-based PN. We hope it can become an integral part in sexual health care for reaching high risk populations with $\mathrm{Ct}$ screening and treatment which is important for both the individual and public health level.

\section{Abbreviations}

Ct: Chlamydia trachomatis; GPs: General practitioners; IM: Intervention mapping; PAPM: Precaution adoption process model; PN: Partner notification; STI: Sexually transmitted infection.

\section{Competing interests}

The authors declare that they have no competing interests.

\section{Authors' contributions}

$K T$ carried out the study, participated in the design of the study, performed the analyses and drafted the manuscript. ND supervised the study, designed the study and drafted the manuscript. CH, RC, CKZ, NV, MS and JB participated in the design of the study and helped draft the manuscript. $\mathrm{CH}$, RC, CKZ and NV further importantly contributed to interpretation of results. All authors read and approved the final manuscript.

\section{Acknowledgements}

This study was funded by the Public Health Care Services South Limburg. The authors gratefully thank the sexual health nurses Eveline van der Veen and Marga Smit (Public Health Services South Limburg) for their practicebased contribution during the project meetings. We also thank all other sexual health care nurses (Public Health Services South Limburg) for their time and effort in planning the semi-structured interviews and all study participants for their time. Lastly, we thank especially Prof. dr. Gerjo Kok (University of Maastricht) for helping to draft the manuscript and critically reviewing the IM process, drs. Pim Schipper (Mondriaan) for analysing the semi-structured interviews, dr. Ingrid van den Broek (RIVM) and drs. Loes Senssen (Public Health Services South Limburg) for their participation as an expert.

\section{Author details}

Department of Sexual Health, Infectious Diseases and Environmental Health, Public Health Services South Limburg, Geleen, The Netherlands. ${ }^{2}$ Department of Medical Microbiology Maastricht Infection Centre (MINC), School for Public Health and Primary Care (CAPHRI), Maastricht University Medical Centre (MUMC+), Maastricht, The Netherlands. ${ }^{3}$ Department of Health Promotion, School for Public Health and Primary Care (CAPHRI), Maastricht University Medical Centre (MUMC+), Maastricht, The Netherlands. ${ }^{4}$ In-Fact, Bradford, UK. ${ }^{5}$ Centre for Infectious Disease Control, RIVM National Institute of Public Health and the Environment, Bilthoven, The Netherlands. ${ }^{6}$ The national institute for STI and AIDS Control, Amsterdam, The Netherlands. ${ }^{7}$ Department of General Practice, AMC-University of Amsterdam, Amsterdam, The Netherlands. ${ }^{8}$ Julius Centre for Health Sciences and Primary Care, University Medical Centre Utrecht, Utrecht, The Netherlands.

Received: 11 December 2012 Accepted: 15 October 2013 Published: 22 October 2013

\section{References}

1. National Institute for Public Health and the Environment: Nationaal soa/ hiv-plan 2012-2016: 'bestendigen en versterken. 2011:13,14, 18,19. Report 215111001/2011 Bilthoven http://www.rijksoverheid.nl/documenten-enpublicaties/rapporten/2011/12/05/nationaal-soa-hiv-plan-2012-2016bestendigen-en-versterken.html. 
2. Soetens LC, Koedijk FDH, van den Broek IVF, Vriend HJ, Op de Coul ELM, van Sighem Al, Stirbu-Wagner I, van Benthem BHB: STI, including HIV, in the Netherlands in 2012. 2011:3-51. Annual Report 150002003 Bilthoven http://www.rivm.nl/Documenten_en_publicaties/Wetenschappelijk/ Rapporten/2013/juni/Sexually_transmitted_infections_including_HIV_in_ the_Netherlands_in_2012.

3. Geisler WM: Duration of Untreated, Uncomplicated Chlamydia trachomatis Genital Infection and Factors Associated with Chlamydia Resolution: a Review of Human Studies. JID 2010, 201(Suppl 2):s104-s113.

4. Wand H, Guy R, Donovan B, McNulty A: Developing and validating a risk scoring tool for chlamydia infection among sexual health clinic attendees in Australia: a simple algorithm to identify those at high risk of chlamydia infection. BMJ Open 2011, 1:e000005. Doi:10.1136/bmjopen-2010-000005.

5. Haggerty CL, Gotliebb SL, Taylor BD, Low N, Xu F, Ness RB: Risk of Sequelae after Chlamydia trachomatis Genital Infection in Women. JID 2010, 201(Suppl2):s134-s155

6. Novak DP, Karlsson BR: Simplifying chlamydia testing: an innovative Chlamydia trachomatis testing approach using the internet and a home sampling strategy: population based study. Sex Trans Infect 2006 82:142-147. doi: 10.1136/sti.2005.016832.

7. Novak D, Novak M: Use of the Internet for home testing for Chlamydia trachomatis in Sweden: who are the users? Int J of STD AIDS 2012, 23:83-87. Doi:10.1258/ijsa.2011.011030.

8. Bracebrigde S, Bachmann MO, Ramkhelawon K, Woolnough A: Evaluation of a systematic postal screening and treatment service for genital Chlamydia trachomatis, with remote clinic access via the internet: a cross-sectional study, East of England. Sex Trans Infect 2012, 88(5):375-381. Doi:10.1136/sextrans-2011-050267.

9. Gaydos CA, Dwyer K, Barnes M, Rizzo-Price PA, Wood BJ, Flemming T, Hogan MT: Internet-Based Screening for Chlamydia trachomatis to Reach Nonclinic Populations With Mailed Self-Administered Vaginal Swabs. Sex Trans Dis 2006, 33(7):451-457. doi: 10.1097/01.olq.0000200497.14326.fb.

10. Van Den Broek IVF: Chlamydia Screening Implementation Netherlands, Impact evaluation and cost-effectiveness. National Institute for Public Health and the Environment (RIVM). 2010:22,113. Report 210261008 Bilthoven http://www.rivm.nl/bibliotheek/rapporten/210261008.html.

11. Jenkins WD, Weis R, Campbell P, Barnes M, Barnes P, Gaydos C: Comparative effectiveness of two self-collected sample kit distribution systems for Chlamydia screening on a university campus. Sex Trans Infect 2012, 88:363-367.

12. Mishra S, Sgaier SK, Thompson LH, Moses S, Ramesh BM, Alary M, Wilson D, Blanchard JF: HIV epidemic appraisals for assisting in the design of effective prevention programmes: shifting the paradigm back to basic. Plos One 2012, 7(3):e32324. doi: 10.1371/journal.pone.0032324

13. Aral SO, Leichliter JS, Blanchard JF: Overview: the role of emergent properties of complex systems in the epidemiology and prevention of sexually transmitted infections including HIV infection. Sex Trans Infect 2010, 86(Suppl3):iii1-iii3.

14. Robinson K, Cohen T, Colijn C: The dynamics of sexual contact networks: effects on disease spread and control. Theor Pop Biol 2012, 81(2). Doi:10.1016/j.tpb.2011.12.009.

15. Drumright LN, Frost SDW: Rapid social network assessment for predicting HIV and STI risk among men attending bars and clubs in San Diego California. Sex Trans Infect 2010, 86(3):iii17-iii23.

16. Rothenberg R: The tranformation of Partner Notification. CID 2002, 35(2):S138-S145

17. Youm Y, Laumann EO: Social Network Effects on the Transmission of STI. Sex Trans Dis 2002, 29(11):689-697.

18. Wejnert C, Heckathorn DD: Web-Based Network Sampling: efficiency and Efficacy of RDS. Soc Meth Res 2008, 37:105-134.

19. Malekinejad M, Johnston LG, Kendall C, Kerr LRFS, Rifkin MR, Rutherfors GW: Using Respondent-Driven Sampling Methodology for HIV Biological and Behavioral Surveillance in International Settings: a systematic review. AIDS Behav 2008, 12:S105-S130.

20. Heckathorn DD, Semaan S, Broadhead RS, Hughes JS: Extensions of respondent-driven sampling: A new approach to the study of injection drug users aged 18-25. AIDS Behav 2002, 6:55-67.

21. Johnston $L G$, Whitehead $S$, Simic-Lawson $M$, Kendall C: Formative research to optimize respondent dirven sampling surveys among hard-to-reach populations in HIV behavioral and biological surveillance: lessens learned from four case studies. AIDS Care 2010, 22(6):784-792.
22. Bartholomew LK, Parcel GS, Kok G, Gottlieb NH, Fernandez ME: Planning health promotion programs: an intervention mapping approach. United States of America: John Wiley \& Sons; 2011.

23. van Oostrom SH, Anema JR, Terluin B, Venema A, de Vet HCW, van Mechelen W: Development of a workplace intervention for sick-listed employees with stress-related mental disorders: intervention Mapping as a useful tool. BMC Health Serv Res 2007, 7:12. doi: 10.1186/1472-6963-7-127.

24. Wolfers MEG, van den Hoek C, Brug J, de Zwart O: Using Intervention Mapping to develop a programme to prevent sexually transmittable infections, including HIV, among heterosexual migrant men. BMC Public Health 2007, 7:141. doi: 10.1186/1471-2458-7-141.

25. van Empelen P, Kok G, Schaalma HP, Bartholomew LK: An AIDS Risk Reduction Program for Dutch Drug Users: An Intervention Mapping Approach to Planning. Health Promot Pract 2003, 4(4):402-412. doi: $10.1177 / 1524839903255421$.

26. Green LW, Kreuter MW: Health Program Planning: An Educational and Ecological Approach. 4th edition. NY: McGraw-Hill Higher Education; 2005.

27. Central Committee on Research inv. Human Subjects (CCMO). http://www. $\mathrm{ccmo}-$ online. $\mathrm{n} / \mathrm{main}$.asp? pid $=43 \&$ thid $=57 \&$ catid $=2$.

28. Weinstein ND, Sandman PM: A model of the Precaution Adoption Process: Evidence From Home Radon Testing. Health Psychol 1992, 11(3):170-180.

29. van Bergen J, Gotz HM, Richardus JH, Hoebe CJPA, Broer J, Coenen AJT: Prevalence of urogenital Chlamydia trachomatis increases significantly with level of urbanisation and suggests targeted screening approaches: results from the first national population based study in the Netherlands. Sex Trans Infect 2005, 81:17-23. doi: 10.1136/sti.2004.010173.

30. Trienekens SCM, Vriend HJ, Koedijk FDH, Van Den Broek IVF, Vriend HJ, Op De Coul ELM, Van Veen MG, Van Sighem Al, Stirbu Wagner I, Van Der Sande MAB: Sexually transmitted infections, including HIV, in the Netherlands in 2011. National Institute of Public Health and the Environment (RIVM). 2012:39-49. Annual Report 201051001 Bilthoven http://www.rivm.nl/ Documenten_en_publicaties/Wetenschappelijk/Rapporten/2012/juni/ Sexually_transmitted_infections_including_HIV_in_the_Netherlands_in_2011.

31. Greenland KE, Op De Coul ELM, Van Bergen JEAM, Brouwers EEHG, Fennema HJSA, Gotz HM, Hoebe CJPA, Koekenbier RH, Pars LL, Van Ravesteijn SM, Van Den Broek IVF: Acceptability of the Internet-Based Chlamydia Screening Implementation in the Netherlands and Insights Into Nonresponse. Sex Trans Dis 2011, 38:6.

32. Potard C, Courtois R, Rusch E: The influence of peers on risky sexual behaviour during adolescence. Eur J Contracept Reprod Health Care 2008, 13(3):264-270.

33. Fichtenberg CM, Muth SQ, Brown B, Padain NS, Glass TA, Ellen JM: Sexual network position and risk of sexually transmitted infections. Sex Trans Dis 2009, 85:493-498. doi: 10.1136/sti.2009.036681.

34. Brewer D: Case-finding effectiveness of partner notification and cluster investigation for sexually transmitted diseases/HIV. Sex Trans Dis 2005, 32(2):78-83.

35. Samkange-Zeeb FN, Spallek L, Zeeb H: Awareness and knowledge of STIs among school-going adolescents in Europe: asystematic review of published literature. BMC Public Health 2011, 11:727.

36. Centers for Disease Control and Prevention: Summary of a review of the literature: Programs to Promote Chlamydia Screening. http://www.cdc.gov/ STI/HealthComm/ChlamydiaLitReview2008.pdf

37. Tilson EC, Sanchez V, Ford CL, Smurzynski M, Leone PA, Fox KK, Irwin K, Miller WC: Barriers to asymptomatic screening and other STD services for adolescents and young adults: focus group discussions. BMC Public Health 2004, 21(4):1-8.

38. Barth KR, Cook RL, Downs JS, Switzer GE, Fischhoff B: Social Stigma and Negative Consequences: Factors That influence College Students' Decisions to Seek Testing for Sexually Transmitted Infections. J of Am Coll Health 2003, 50(4):153-159.

39. Blake D, Kearney M, Oakes JM, Druker S, Bibace R: Improving participation in chlamydia screening programs: perspectives of high-risk youth. Arch Pediatr Adolesc Med 2003, 157:523-529.

40. Gotz HM, Veldhuijzen IK, van Bergen JEAM, Hoebe CJPA, de Zwart O, Richardus JH: Acceptability and Consequences of Screening for Chlamydia trachomatis by Home-Based Urine Testing. Sex Trans Dis 2005, 32(9):557-562. doi: 10.1097/01.olq.0000175416.15905.db.

41. Østergaard L, Andersen B, Møller JK, Olesen F, Worm AM: Managing partners of people diagnosed with Chlamydia trachomatis: a comparison of two partner testing methods. Sex Transm Infect 2003, 79:358-362. 
42. Temple-Smith M, Hopkins C, Fairley C, Tomnay J, Pavlin N, Parker R, Russell D, Bowden F, Hocking J, Pitts M, Chen M: The right thing to do: patients' views and experiences of telling partners about chlamydia. Fam Pract 2010, 27:418-423. doi: 10.1093/fampra/cma028.

43. Bilardi JE, Fairley CK, Hopkins CA, Hocking JS, Temple Smith MJ, Bowden FJ, Russell DB, Pitts M, Tomnay JE, Parker RM, Pavlin NL, Chen MY: Experiences and Outcomes of Partner Notification Among Men and Women Recently Diagnosed With Chlamydia and Their Views on Innovative Resources Aimed at Improving Notification Rates. Sex Trans Dis 2010, 37:4.

44. Burnet Institute: Partner Notification of Sexually Transmitted Infections in New South Wales: an informed literature review. http://www.stipu.nsw.gov.au/ content/Document/NSW_STI_PN_PDF.pdf.

45. Rothenberg RB, Sterk C, Toomey KE, Potterat JJ, Johnson D, Schrader M, Hatch S: Using Social Network and Ethnographic Tools to Evaluate Syphilis Transmission. Sex Trans Dis 1998, 25(3):154-160.

46. Choi KH, Ning Z, Gregorisch SE, Pan QP: The Influence of Social and Sexual Networks in the Spread of HIV and Syphilis Among Men Who Have Sex With Men in Shanghai. Epidemiol Soc Sci 2007, 45(1):77-84.

47. Trelle S, Shang A, Nartey L, Cassell JA, Low N: Improved effectiveness of partner notification for patients with sexually transmitted infections: systematic review. BMJ 2007, 334(7589):354.

48. Jenkins WD, Wold B: Use of the Internet for the surveillance and prevention of sexually transmitted diseases. Microbes Infect 2012, 14:427-437.

49. Levine D, Woodruff AJ, Mocello AR, Lebrija J, Klausner JD: inSPOT: The First Online STD Partner Notification System Using Electronic Postcards. Plos Med 2008, 5(10):213.

50. Alam N, Chamot E, Vermund SH, Streatfield K, Kristensen S: Partner notification for STI in developing countries: a systematic review. BMC Public Health 2010, 10(19):1471-2458.

51. Hogben M, Kissinger P: A Review of Partner Notification for Sex Partners of Men Infected With Chlamydia. Sex Trans Dis 2008, 35(11):S34-S39.

52. Rogers WA: Ethical issues in public health: a qualitative study of public health practice in Scotland. J Epidemiol Community Health 2004, 58:446-450. Doi:10.1136/jech.2003.013417.

doi:10.1186/1471-2458-13-996

Cite this article as: Theunissen et al:: Using intervention mapping for the development of a targeted secure web-based outreach strategy named SafeFriend, for Chlamydia trachomatis testing in young people at risk. BMC Public Health 2013 13:996.

\section{Submit your next manuscript to BioMed Central and take full advantage of:}

- Convenient online submission

- Thorough peer review

- No space constraints or color figure charges

- Immediate publication on acceptance

- Inclusion in PubMed, CAS, Scopus and Google Scholar

- Research which is freely available for redistribution 